\title{
Current Status of Neonatologist Staffing and Workload in Korean Neonatal Intensive Care Units
}

\author{
Byong Sop Lee, MD, $\mathrm{PhD}^{1,{ }^{*}}$, Jae Woo Lim, MD, $\mathrm{PhD}^{2, *}$, Yong-Sung Choi, $\mathrm{MD}$, $\mathrm{PhD}^{3}$, and Ki-Soo Kim, MD, $\mathrm{PhD}^{1}$ \\ ${ }^{1}$ Department of Pediatrics, Asan Medical Center, University of Ulsan College of Medicine, Seoul, Korea \\ ${ }^{2}$ Department of Pediatrics, Konyang University College of Medicine, Daejeon, Korea \\ ${ }^{3}$ Department of Pediatrics, Kyung Hee University School of Medicine, Seoul, Korea
}

\section{ABSTRACT}

Purpose: To identify the recent status of the neonatologist and their workload in neonatal intensive care unit (NICU) in Korea.

Methods: On October 2018, a survey was conducted on the statistics of the workforce including the census of certified neonatologists, NICU beds, nursing staffing ratings, bed occupancy rate, annual admission of very low birth weight infant (VLBWI), infant acuity score of nursing, and the proportion of out-born patients. The level of neonatal care was self-rated.

Results: A total of 68 centers responded to the survey. An average number of certified neonatologists and the number of NICU beds per center was 1.9 (range, 0 to 5) and 23.1 (range, 0 to 30$)$, respectively. Thirty-eight percent $(\mathrm{n}=26)$ of NICUs were being operated with only one $(\mathrm{n}=24)$ or no $(\mathrm{n}=2)$ certified neonatologist and only $19 \%(\mathrm{n}=13)$ of NICUs had $\geq 3$ neonatologists. The average ratio of NICU beds to neonatologists rated 13.4 \pm 6.2 . The higher the level of neonatal care, the higher the number of tertiary referral hospitals, neonatologists, NICU volume, infant acuity scores of nursing, and annual VLBWI admissions. However, there was no difference in the beds to neonatologist ratio between level $2(n=9,9.5 \pm 3.1)$, level $3(n=44,14.0 \pm 6.9)$, and level $4(\mathrm{n}=14,13.7 \pm 4.2)$. The infant acuity score was proportional to the NICU volumes, but not related to the beds to neonatologist ratio.

Conclusion: Compared with the international standards, most Korean NICUs were understaffed in terms of the certified neonatologist and were unable to provide 'continuity of care' for high-risk newborns.

Key Words: Intensive care, neonatal; Workforce; Level of neonatal care

\section{서론}

신생아의 10\%-15\%는 신생아중환자실(neonatal intensive care unit, NICU)에 입원한다 ${ }^{1)}$. 출 생아 규모에 맞는 NICU 병상을 확보하고 이를 효율적으로 운영하기 위한 인적 물적 인프라를
Received: 22 January 2020

Revised: 20 April 2020

Accepted: 20 April 2020

Correspondence to: Ki-Soo Kim, MD, $\mathrm{PhD}$

Department of Pediatrics, Asan Medical Center, University of Ulsan College of Medicine, 88 Olympic-ro 43-gil, Songpa-gu, Seoul 05505, Korea

Tel: +82-2-3010-3377

Fax: +82-2-3010-6978

E-mail: kskim@amc.seoul.kr

*Byong Sop Lee and Jae Woo Lim contributed equally to this study as first authors.

Copyright(c)

By Korean Society of Neonatology.

All right reserved.

This is an Open-Access article distributed under the terms of the Creative Commons At tribution Non-Commercial License (http:// creativecommons.org/licenses/by-nc/4.0), which permits unrestricted non-commercial use, distribution, and reproduction in any medium, provided the original work is properly cited. 
확보하는 것은 영아 생존율 향상을 위한 필수 보건 정책이다. 1995 년 이후 2010년 이전까지 전국 NICU 인력 및 시설 운영 현황에 대하 여 대한신생아학회 주도로 몇 개의 연구들이 발표되었고 일관된 결 론은 다음과 같았다2-6). 비록 출생아 수는 지속적으로 감소하는 추 세지만 고위험 산모와 조산아 등 고위험 신생아 상대적 비율은 증 가하고 있다. 따라서 NICU 병상 확보를 위한 국가적 지원이 절실 하다. 최근 십 년간 학회와 정부는 출생아 1,000 명당 NICU 병상 수 3.4-4.3 확보를 목표로 함께 노력해 왔다 ${ }^{4,7)}$. 정부 주도 신생아 집 중치료 지역센터 사업과 고위험 산모-신생아 통합치료센터 사업이 2008년과 2013년에 각각 시행되었다. 더불어 2013년 NICU 입원 수 가가 현실화 되는 등 전폭적인 제도적 지원도 뒷받침되었다. 신생 아 진료 인프라 확충이 우리나라 신생아 사망률 감소와 미숙아 생존 율 향상이라는 결과에 크게 기여한 것은 부정할 수 없다. 1993년 출 생아 1,000명당 9.9명이던 영아 사망률은 2017년 2.8로 감소하였다. 신생아 중환자 치료 수준의 대표적 지표인 극소 저체중출생아(very low birth weight infant, VLBWI) 생존율도 꾸준히 향상되어 85\%에 이르렀다 ${ }^{8,9)}$.

그런데 저출산 기조가 악화되면서 2017년을 기점으로 연간 출생 아 수 40 만 명 선이 무너졌고 30 만 명 선 붕괴라는 위기감이 감돌 고 있다. 따라서 비록 저체중아 비율의 증가 추세는 지속되지만 전 체 분모인 출생아 수의 급격한 감소로 인해 2016년 이후로 출생체 중 $2.5 \mathrm{~kg}$ 및 $1.5 \mathrm{~kg}$ 미만의 고위험 신생아 숫자도 감소하고 있다 ${ }^{10)}$. 따라서 최근 수년 내 자료를 보면 전국적으로 NICU 병상 수는 수요 에 근접했거나 오히려 초과한 것으로 보인다. 2015년 연구는 국내 출생아 438,420명, 전국 NICU 병상 수는 1,710 개로 이를 바탕으로 조사된 1,000명 신생아당 NICU 병상 수는 3.9였고 이는 앞서 언급 한 적정 병상 수 범위에 포함되는 결과이기 때문이다 ${ }^{5,711}$. 이 수치 는 최근 출생아 수 감소 추세를 감안하면 더 높을 것으로 예상할 수 있다. NICU 병상이 없어 제대로 치료받지 못한 아기의 소식은 더 이 상 들리지 않는다. 그럼에도 불구하고 VLBWI 생존율은 2010년 이 후로 $85 \%$ 의 벽을 깨지 못하고 있고 출생체중 $1,000 \mathrm{~g}$ 미만 또는 재 태주령 26주 이하 초미숙아 치료 성적은 일본 등 외국 성적에 미치 지 못한다 ${ }^{8,9)}$.

충분한 NICU 병상과 시설 확보에도 불구하고 우리나라 고위험 신생아 생존율이 제자리걸음인 근본적 원인은 무엇일까? 국내 연구 자들은 NICU의 인력 부족과 지역별 의료 공급 불균형, 비효율적 의 료 전달체계를 이구동성으로 말한다 ${ }^{7,11,12)}$. 특히 VLBWI의 생존율과 예후 향상을 위해서는 소위 "golden minutes"라고 불리는 출생 직후 의 소생술을 포함한 생후 초기의 안정화 과정이 가장 중요하다. 이 과정을 매끄럽게 수행할 수 있는 충분한 수의 숙련된 신생아 전문의 (certified neonatologist) 또는 NICU 전담 의사가 전국에 효율적으로 분포되어 24 시간 높은 수준의 의료 서비스를 제공할 수 있도록 하는 정책이 필요하다. 그러나 우리나라 신생아 전문의 1 인당 담당 $\mathrm{NICU}$
병상 수는 국제적 기준을 크게 초과하고 있으며, 지난 10년간 NICU 병상 수가 늘면서 오히려 악화되는 추세를 보인다 ${ }^{11-13)}$. 또한 신생아 치료 등급(level of neonatal care), 입원 환아의 간호 중증도(infant acuity of nursing) 등 NICU 업무 강도에 따른 신생아 전문의 인력 운 영에 대한 자료도 부족하다.

본 연구의 목적은 전국 NICU의 신생아 전문의 인력과 이와 관련 된 병상 운영 실태를 확인하고 향후 국내 NICU 등급화 및 의료전달 체계 정책 수립에 필요한 인력 관련 기초자료를 마련하는 것이다.

\section{대상 및 방법}

2018년 10월 신생아학회 회원이 속한 전국 71개 NICU 운영 병 원에 “신생아중환자실 인력 및 병상 운영에 대한 설문조사” 표제의 설문을 각 NICU 책임 신생아 전문의(신생아 전문의 부재 시는 부 서 담당 소아청소년과 전문의)에게 전송 후 회수하였다. 본 설문조 사연구는 서울아산병원 임상연구심의위원회의 심의면제 확인 승인 을 받았다(과제번호 2020-0337). 기본 소속 병원 정보 이외에 다음 과 같은 설문 항목이 포함되었다. 신생아분과 전문의(이하 신생아 전문의) 수, 상급종합병원 지정 여부, 2018년 개정된 기준에 따른 NICU 간호등급, 신고 NICU 병상 수, 병상 가동률, NICU 치료 등급, 연간 VLBWI 입원 수, 간호 중증도(이하 설명), 재원 환자 중 외부 환 자 비율이었다. 설문 상의 편의를 위하여 병상 가동률, VLBWI 입원 수, 외부 신환 비율은 구간 범위를 제시하고 한 가지를 선택하도록 하였다. 병상 가동률은 2017년과 2018년 상반기를 기준으로 각각 조사하였으며, 나머지 값은 2017년을 기준으로 조사하였다.

NICU 치료 등급은 2012년 미국 소아과학회(American Academy of Pediatrics, AAP)에서 제시된 Policy Statement Levels of Neonatal Care에 따라 각각 level I (well newborn nursery), II (special care nursery), III (NICU), IV (regional NICU)로 구분하였다 ${ }^{14}$. 간호 중 증도는 Operational Definitions of Infant Acuity Levels Originally Described by AAP/American College of Obstetricians and Gynecologists를 기준으로 하였으며 소속 NICU의 평균적인 환자 중증도 를 5가지 항목(1, continuing care; 2, requiring intermediate care; 3 , requiring intensive care; 4, requiring multi-system support and unstable; 5, requiring complex critical care)으로 구분하여 각 비율 의 총합이 $100 \%$ 가 되도록 작성하였다 ${ }^{15)}$. 이를 바탕으로 환자 중증 도를 각 항목 값별 비례를 이용하여 계산하였으며 최소값은 1 , 최 대값은 5였다(예, acuity $1,10 \% ; 2,20 \% ; 3,40 \% ; 4,20 \% ; 5,10 \%$ 인 NICU의 acuity는 $1 \times 0.1+2 \times 0.2+3 \times 0.4+4 \times 0.2+5 \times 0.1=3.0$ ).

집단 간 연속변수 비교에 대하여는 Kruskal-Wallis 법을, 비연속 변수에 대하여는 two-by-K 또는 R-by-C 교차분석을 시행하였으며 linear by linear association을 확인하였다. 변수 간의 상관관계에 대 
한 분석은 Pearson correlation을 이용하였다. 통계 프로그램은 SPSS Statistics version 22.0 (IBM Co., Armonk, NY, USA)을 통해 시행되 었고, $P<0.05$ 를 통계적으로 유의한 것으로 정의하였다.

결과

설문을 보낸 71 개 병원 중 68 개 병원이 설문조사에 답하였고 응답 률은 96\%였다. 상급종합병원 NICU가 37개소(54\%)였고 나머지는 종합병원이었다.

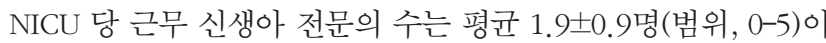
었다. 2 인 근무 NICU가 가장 많았고( $\mathrm{n}=29,43 \%), 1$ 인( $\mathrm{n}=25,37 \%), 3$ 인 $(n=10,15 \%), 4$ 인 $(n=1,2 \%), 5$ 인 $(n=2,3 \%)$ 순이었고 신생아 전문 의가 없는 NICU도 있었다 $(n=2,3 \%)$. 조사된 총 NICU 병상 수의 합 은 1,551 개로 이는 2017년 심사평가원에 등록된 전국 NICU 1,848 병상의 84\%를 차지하였다. 병원당 NICU 병상 수는 평균 23.1(범 위, 6-60)이었다. 10-19병상 규모 NICU가 $(n=25,37 \%)$ 가장 많았고, 다음으로 20-29병상 규모 $(n=20,29 \%)$ 였다. 10병상 미만의 소규모 $\mathrm{NICU}$ 는 5개(7\%), 30-39병상 10개(15\%), 40병상 이상은 8개(12\%)

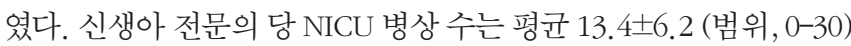
였다. 10-19 구간에 포함된 병원이 가장 많았고 1 인당 NICU 병상 비 율이 10 명 미만인 NICU는 18 개로 전체의 $27 \%$ 에 불과하였으며 이 비율이 30 인 곳도 2개소가 있었다(Figure 1).

간호등급은 2 등급이 전체의 $60 \%$ 로 가장 많았다. 상급 종합병원 과 종합병원 간 등급 기준 차이는 없었다. 상급종합병원은 2 등급인 곳이 가장 많았고 $(n=17,57 \%), 3$ 등급 $(n=7,23 \%), 4$ 등급 $(n=5,17 \%)$ 순이었다. 1 등급인 곳은 1 곳 $(2 \%)$ 에 불과하였다. 종합병원의 경우 도 이와 유사하게 2 등급 $(n=24,65 \%), 3$ 등급 $(n=8,22 \%), 4$ 등급 $(n=3$, $8 \%), 1$ 등급 $(\mathrm{n}=2,5 \%)$ 순이었다.

급격한 출생아 감소가 병상 가동률에 미치는 영향을 확인하기 위
하여 2017년과 2018년 상반기 병상 가동률을 비교하였다. 2017년에 는 90\%-99\% 사이 구간이 2018년 상반기는 70\%-79\%가 가장 많은 비율을 차지하였다. NICU별로 병상 가동률은 50\% 미만에서 $100 \%$ 이상까지 큰 편차를 보였으나 1 년 새 병상 가동률의 변동은 크지 않 았다. 약 반 수의 NICU는 병상 가동률 구간 변화가 없었고 병상 가 동률이 증가한 곳과 $(n=17,25 \%)$, 감소한 곳 $(n=20,19 \%)$ 의 숫자는 비 슷하였다(Figure 2).

2017년 VLBWI 입원 수는 20-49명 구간이 가장 많았고(n=30, 44\%) 10-19명(n=12, 18\%), 50-99명(n=11, 16.2\%), 1-9명(n=9, 13 $\%), 100$ 명 이상 $(\mathrm{n}=5,7 \%)$ 순이었다. VLBWI 입원이 한 명도 없는 곳 이 1 곳 $(2 \%)$ 있었다. 계산된 간호 중증도의 평균값은 $2.6 \pm 0.5$ 이었고 최소 1.5 에서 최대 4.2 의 격차를 보였다. NICU 치료 등급은 level 3 $(\mathrm{n}=44,65 \%)$ 이 가장 많았고, level $4(\mathrm{n}=15,22 \%)$, level $2(\mathrm{n}=9,13 \%)$ 의 순서였다.

$\mathrm{NICU}$ 치료 등급별 인력 및 병상 운영 현황을 분석하였다. 치료 등급이 높을수록 상급종합병원 비율 $(P<0.001)$, 간호등급 $(P=0.010)$, $\mathrm{NICU}$ 근무 신생아 전문의 수 $(P<0.001), \mathrm{NICU}$ 병상 수 $(P<0.001)$, 간

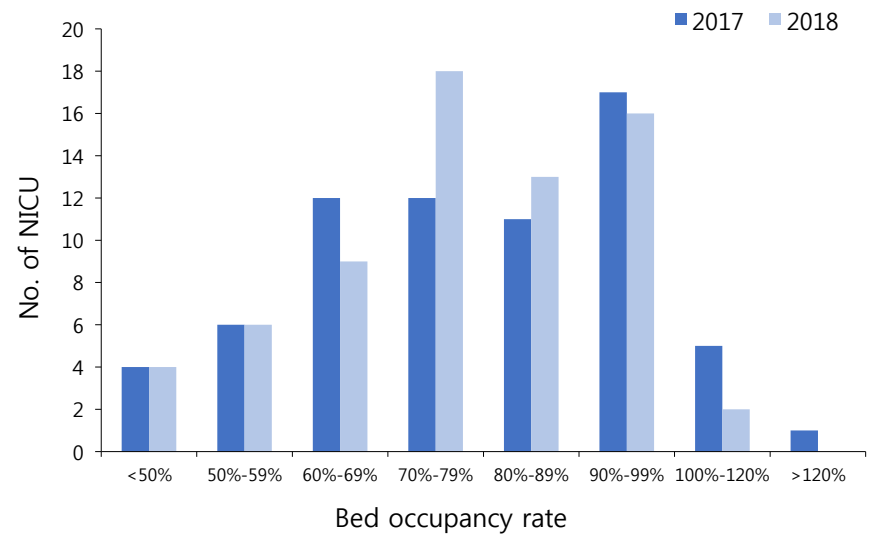

Figure 2. Change in neonatal intensive care unit (NICU) bed occupancy rate from 2017 to 2018 in Korea.

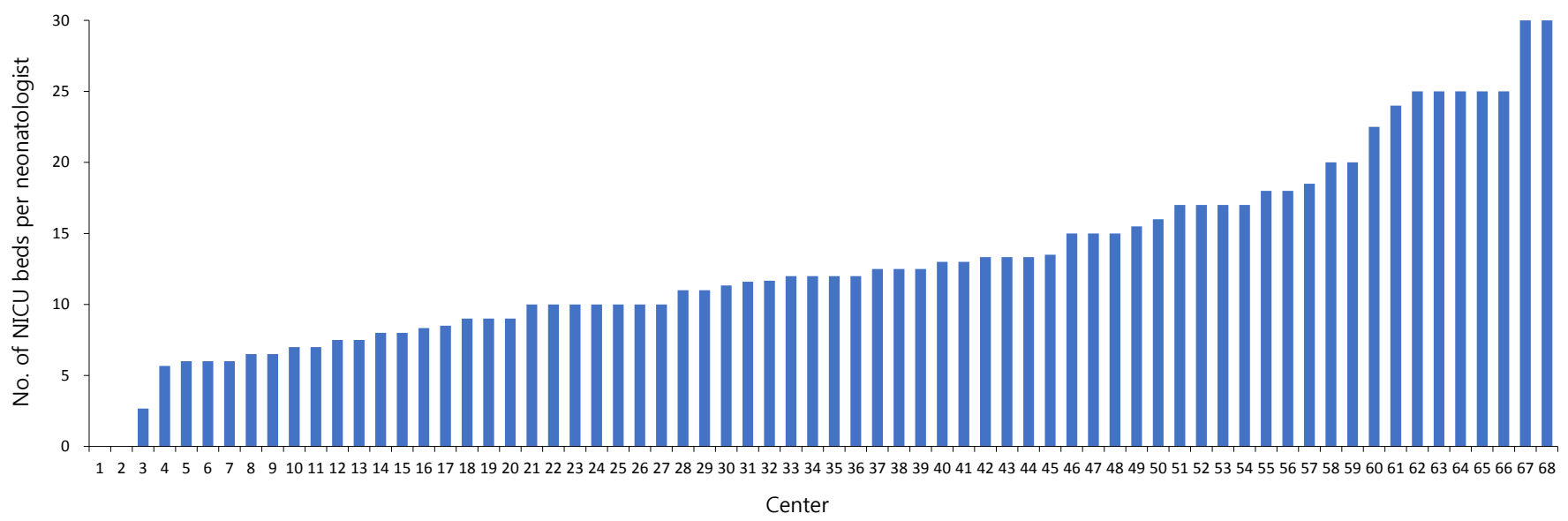

Figure 1. Number of neonatal intensive care unit (NICU) beds per neonatologist in 68 Korean centers in 2018. 
Table 1. Characteristics of NICU Statistics and Levels of Neonatal Care

\begin{tabular}{lcccc}
\hline Variable & $\begin{array}{c}\text { Level 2 } \\
(\mathrm{n}=9)\end{array}$ & $\begin{array}{c}\text { Level 3 } \\
(\mathrm{n}=44)\end{array}$ & $\begin{array}{c}\text { Level 4 } \\
(\mathrm{n}=15)\end{array}$ & $P$-value \\
\hline No. of neonatologists & $1.22 \pm 0.83$ & $1.66 \pm 0.61^{*}$ & $2.87 \pm 1.13^{*}$ & $<0.001$ \\
NICU volume & $13.8 \pm 8.3$ & $20.4 \pm 7.3^{*}$ & $37.5 \pm 13.3^{*}$ & $<0.001$ \\
No. of NICU beds per & $9.7 \pm 3.0$ & $13.9 \pm 6.9$ & $13.7 \pm 4.2$ & 0.116 \\
$\quad$ neonatologist & & & & \\
Mean infant acuity score & $2.24 \pm 0.46$ & $2.59 \pm 0.39$ & $2.83 \pm 0.61$ & 0.042
\end{tabular}

Values are expressed as mean \pm standard deviation. By Kruskal-Wallis test.

${ }^{*} P<0.001$ by Mann-Whitney test for comparison of level 3 and level 4 . Abbreviation: NICU, neonatal intensive care unit.

A

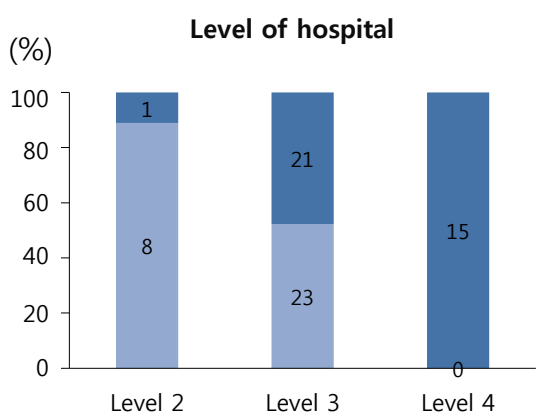

$P<0.001$

- Tertiary hospital

- General hospital

\section{C} (\%) No. of NICU beds per neonatologist

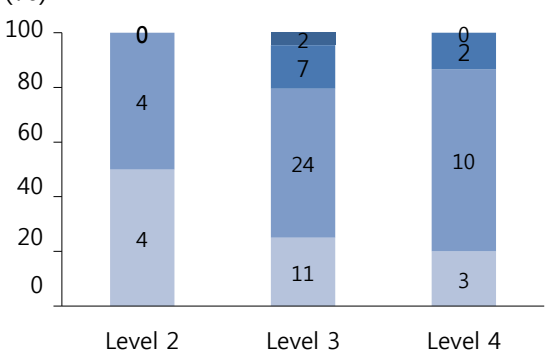

E

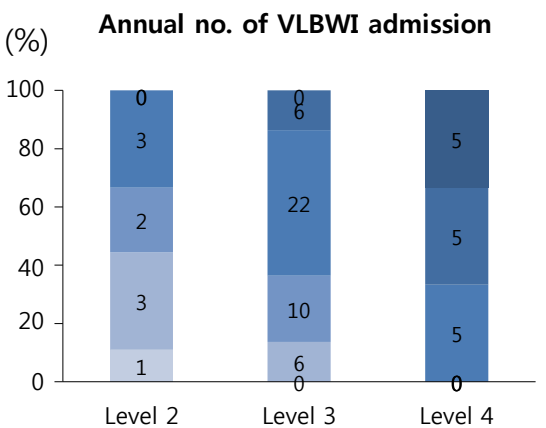

$P=0.190$
호 중증도 $(P=0.042)$, 병상 가동률 $(P=0.001)$, 연간 VLBWI 입원 수 $(P<0.001)$ 가 유의하게 높았다. 외부 환자 입원 비율 $(P=0.876)$ 은 차 이가 없었다. 그러나 각 등급별 신생아 전문의 당 NICU 병상 수는 차이가 없었으며 $(P=0.116)$ 통계적으로 유의하지는 않았으나 level 3 또는 level 4 에 비하여 level 2 가 오히려 비율이 낮은 경향을 보였 다(Table 1, Figure 3). Level 2 NICU를 제외하고 level 3와 level 4를 비교하였다. Level 4 NICU는 level 3 NICU에 비하여 근무 신생아

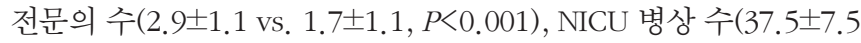
Vs. 20.4 $\pm 0.4, P<0.001)$, 병상 가동률 $(P=0.003)$, 연간 VLBW 입원 수 $(P<0.001)$ 가 유의하게 높았다. 그러나 간호인력 등급 $(P=0.090)$, 신 생아 의사당 $\mathrm{NICU}$ 병상 수 $(P=0.714)$, 간호 중증도 $(P=0.163)$ 의 차이 는 없었다.

환자 중증도와 NICU 병상 수는 양의 상관관계를 보였다 $(r=0.278$,

B

(\%)

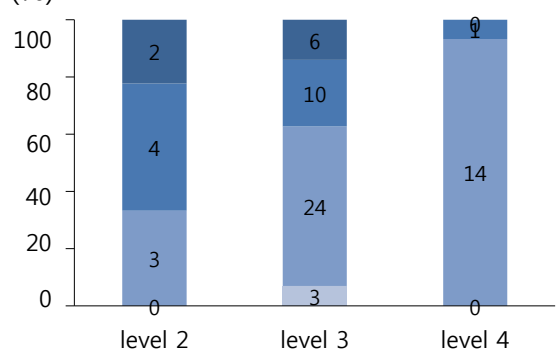

$P=0.024$

- Grade 4

- Grade 3

Grade 2

Grade 1

D

Bed occupancy rate

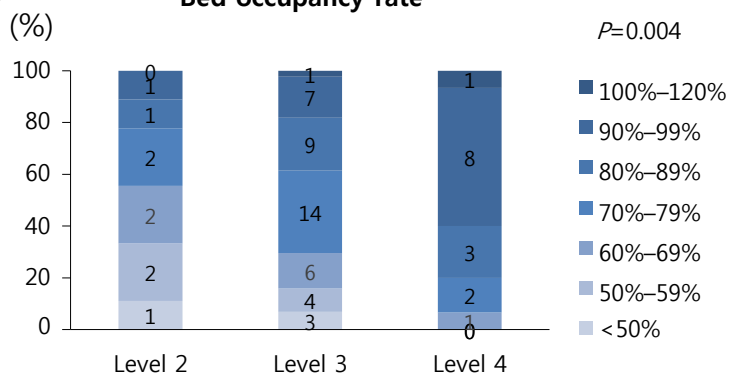

F

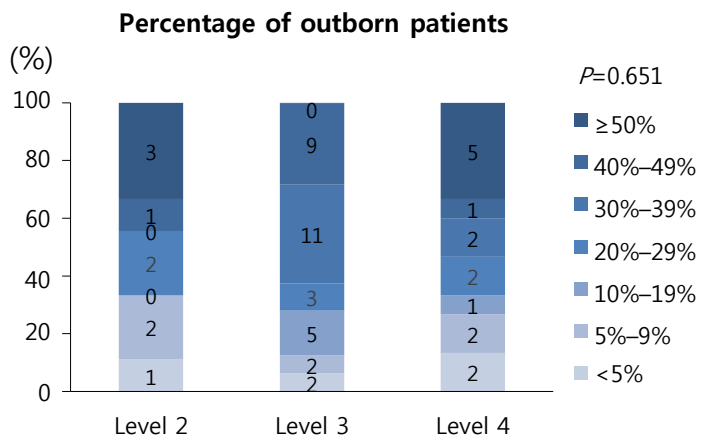

Figure 3. Comparison of parameters of workforce and operation status between the three levels of neonatal care in Korean neonatal intensive care units (NICUs). (A) Level of hospital, (B) nurse staffing grade, (C) number of NICU beds per neonatologist, (D) bed occupancy rate, (E) annual number of very low birth weight infant (VLBWI) admission, and (F) percentage of outborn patients. 
Table 2. Comparison of Number of Neonatologists, NICU Beds, and Patient Acuity between Regions in Korea, 2018

\begin{tabular}{|c|c|c|c|c|c|c|c|}
\hline City or province & $\begin{array}{c}\text { Seoul, } \\
\text { Incheon, } \\
\text { Gyeonggi-do } \\
(n=36)\end{array}$ & $\begin{array}{c}\text { Busan, Ulsan, } \\
\text { Gyeongsangnam- } \\
\text { do } \\
(n=11)\end{array}$ & $\begin{array}{c}\text { Daegu, } \\
\text { Gyeongsangbuk- } \\
\text { do } \\
(n=5)\end{array}$ & $\begin{array}{l}\text { Daejeon, Sejong, } \\
\text { Chungchung nam/ } \\
\text { buk-do } \\
(\mathrm{n}=5)\end{array}$ & $\begin{array}{l}\text { Gwangju, } \\
\text { Jeolla nam/ } \\
\text { buk-do } \\
(\mathrm{n}=6)\end{array}$ & $\begin{array}{l}\text { Gangwon-do } \\
\qquad(\mathrm{n}=2)\end{array}$ & $\begin{array}{c}\text { Jeju-do } \\
(\mathrm{n}=1)\end{array}$ \\
\hline NICU volume & $20(6-60)$ & $20(13-34)$ & $13(6-37)$ & $30(24-34)$ & $20(12-45)$ & $16.5(13-20)$ & 16 \\
\hline Beds to neonatologist ratio & $11.8(2.7-25)$ & $11.3(5.7-24)$ & $12(6-18.5)$ & $25(12-30)$ & $12.5(6-25)$ & $11.5(10-13)$ & 16 \\
\hline
\end{tabular}

Values are expressed as median (range).

*Data from median values from each range.

Abbreviation: NICU, neonatal intensive care unit.

$P=0.033)$. 그러나 환자 중증도는 각각 신생아 전문의 당 NICU 병상 수( $r=0.003, P=0.983)$, VLBWI 연간 입원 수 $(r=0.144, P=0.278)$, 간호 인력 등급 $(r=-0.078, P=0.518)$, 외부 환자 비율 $(r=-0.243, P=0.064)$ 과는 상관관계가 없었다.

광역별 비교에서 NICU당 신생아 의사 수, 환자 중증도는 큰 차이 가 없었다. 그러나 대전, 세종, 충청 지역의 병상 가동률과 신생아 전 문의 당 NICU 병상 수가 가장 높았다. 강원도는 병상 가동률이 가장 낮았다(Table 2).

고찰

우리나라 신생아 전문의 업무는 다음과 같이 요약할 수 있다. 약 23병상 규모 level 3 NICU에서 근무하고 병상의 3/4만 환자가 입원 해 있다. 두 명이 일하므로 24시간 상주 시스템은 현실적으로 불가 능하다. 한 달에 VLBWI는 3명 정도 입원하고 별문제 없으면 타원 전원 없이 퇴원할 때까지 돌본다.

본 연구에서 신생아 전문의 1 인당 담당 병상 수는 13.4 로 이는 2006년 전국 조사에서 확인된 22.1보다는 개선된 수준이나 ${ }^{5)}, 2010$ 년대 이후 조사 결과와는 큰 차이가 없었다 ${ }^{11-13)}$. 이 수치는 NICU를 책임 관리하는 소아청소년과 전문의까지 포함시킨 개념인 '전담 전 문의' 기준으로 평가한다면 다소 낮아질 것으로 예상된다. 실제로 2018년 1월 대한신생아학회에서 전국 75개 병원을 대상으로 조사 한 신생아분과 전문의 포함 NICU 전담 전문의 1 인당 NICU 병상 수 는 평균 12.9 (1,722병상/133명)였다(unpublished data). 1985년 미 국소아과학회는 NICU 입원 환자의 중증도, 재원 기간과 신생아 의 사 업무 형태를 고려하여 NICU에서 신생아 전문의 1 인당 적정 환 자 수 기준을 평균 6 명으로 제안한바 있다 ${ }^{16,17)}$. 최근 연구는 아니지 만 2002년 Thompson 등이 국가별 인구자료와 신생아 진료 인력 현 황을 비교하여 발표한 자료에 근거하여 신생아 전문의당 NICU 병 상 수(intensive 및 intermediate)를 계산하면 미국 8.4, 호주 6.9, 캐
나다 8.1이다 ${ }^{18)}$. 이번에 확인된 국내 신생아 전문의당 NICU 병상 수 13.4 는 가까운 일본(7.0)이나 대만(6.3)과 비교해도 거의 두 배 수치 이다(personal communication). 다만 신생아 전문의 1 인이 담당하 는 환자가 적을수록 치료 성적이 좋아진다는 증거는 부족하다. 대 규모 국가별 연구에서도 출생아 수 대비 신생아 전문의가 너무 적은 지역은 신생아 사망률이 증가한다는 결과도 있지만 ${ }^{19)}$, 신생아 전문 의 수는 신생아 생존율과 큰 연관성이 없다는 결과도 있다 ${ }^{20)}$. 그렇지 만 NICU 병상 규모 대비 우리나라의 신생아 전문의 공급은 국제적 표준에 많이 미치지 못한다는 사실은 부인할 수 없다.

국내 NICU의 약 87\%는 level 3 이상의 진료를 제공할 수 있다고 답하였다. 이는 최소한 VLBWI에 대하여 다른 상급 병원으로 이송 하지 않고 인공호흡기 치료를 포함한 포괄적 치료를 제공할 수 있 는 수준이다. 전국적으로 NICU 치료 수준이 상향 평준화되었다고 볼 수 있겠다. 다만 설문에 포함되지 않은 NICU 정보를 감안하여 해 석할 필요가 있다. 예를 들어 같은 level 3 이라 할지라도 소아외과 등 전문 분과 진료가 모두 가능한지 등에 대한 세부 정보는 조사에 포 함되지 않았다. 실제로 2014년 조사에서 우리나라에서 소아외과 전 문의는 대부분 상급 종합병원 30개소 미만에 소속되어 있는 것으로 확인된다 ${ }^{21)}$. 수술을 포함한 VLBWI나 초극소 저체중출생아에 대한 포괄적 치료 등 level 3 안에서도 세분화 된 소위 "level 3B" 이상 수 준에 합당한 치료를 모두 제공할 수 있는지는 본 설문 연구에서 확 인할 수 없었다.

여러 연구를 통해 NICU 진료 수준의 대표적 지표인 VLBWI 생존 율이 NICU의 치료 등급과 연관된 것은 잘 알려져 있다. Level 3 이 상의 NICU에서 분만된 VLBWI의 사망률이 level 2 이하 NICU의 사 망률보다 유의하게 낮다는 것은 1980년대 이후의 대규모 연구의 일 관된 결론이다 ${ }^{22-28)}$. 이 결과는 미숙아 사망 연관 교란변수를 보정 한 최근의 메타분석에서도 확인된다 ${ }^{29)}$. 국내 연구도 동일한 결과를 보였다 ${ }^{11,30)}$. 다만, 기존 국내 연구들은 미국소아과학회 정의 기준의 $\mathrm{NICU}$ 치료 등급 기준을 이용한 것이 아니고 정맥영양, 소아외과 및 흥부외과 수술 제공 여부, 일산화질소, $\mathrm{ECMO}$, 투석 등 치료 수준, 심 
초음파 및 혈액가스 검사 등 여러 항목별 점수 체계를 활용하여 임 의로 level을 정의한 연구 설계상의 한계가 있다.

2017년 기준으로 VLBWI의 연간 입원 수가 50명 이상인 NICU는 전체의 $25 \%, 100$ 명 이상인 곳은 $10 \%$ 미만이었다. 2013년 조사에서 는 우리나라 VLBWI의 약 $47 \%$ 가 연간 VLBWI 분만 건수 50 이상 인 NICU에 입원했다 ${ }^{30}$. NICU 치료 등급 이외에도 연간 입원 수가 VLBWI의 생존율과 밀접한 연관이 있다고 알려져 있다 ${ }^{23-28)}$. Jensen 과 $\operatorname{Lorch}^{25)}$ 의 연구에 따르면 NICU 치료 등급을 보정한 후에도 연 간 50건 이상의 VLBWI 분만 건수가 낮은 사망률 및 중증 뇌실 내 출 혈 빈도와 관련이 있었다. 미국 캘리포니아주 연구에서는 연간 100 건 이상의 VLBWI 분만이 이루어지는 NICU가 사망률이 상대적으로 낮았다 ${ }^{24,28)}$. 이를 근거로 British Association of Perinatal Medicine (BAPM)은 영국 NICU의 연간 VLBWI 입원 수를 100 명 이상 유지하 도록 권고하며 심지어 이 숫자가 50 미만인 경우 “small” NICU로 규 정하면서 NICU를 병합해서라도 VLBWI 입원 수를 상향 조정하도록 하는 규정을 두고 있다 ${ }^{31}$. 이는 VLBWI 진료의 질 유지에는 일정 규 모 이상의 입원 인원 유지가 필요하다는 의견을 반영한다고 볼 수 있다.

우리나라는 NICU 당 평균 1.9 명의 신생아 전문의가 근무하며 신 생아 전문의가 1 인 이하인 NICU가 약 $38 \%, 2$ 인 이하인 NICU가 $80 \%$ 에 달한다. 앞서 언급한 영국의 BAPM 가이드라인은 모든 NICU 는 치료 등급과 무관하게 적어도 하루 12시간 신생아 자문의(neonatal consultant staff)를 두어야 하고 연간 4,000 집중 치료일이 초 과하는 NICU는 24 시간 상주하도록 하는 규정을 둔다 ${ }^{31)}$. 스위스의 Standards for Levels of Neonatal Care in Switzerland에서는 각 치 료 등급 NICU별 세부 의사 인력 기준을 명시하고 있다. 특히 level 3 $\mathrm{NICU}$ 는 적어도 4 인의 신생아 전문의(관리자 1 인, 대체 관리자 1 인 포함)와 2 인의 신생아 수련 전임의를 두도록 하며 이들 중 최소 1 인 은 24 시간 NICU에 상주해야 함은 물론 신생아 전문의는 적어도 15 분 이내 응급 백업이 가능하도록 하고 있다 ${ }^{32)}$. 일본은 인구 100 만 명 당 1 개소 단위로 총합주산기 모자의료센터를 두고 해당 센터의 $\mathrm{NICU}$ 는 24시간 신생아 전문의 진료를 시행하고 있다. 2009년 기준 으로 77 개의 총합주산기 모자의료센터가 운영되고 있었고 이들에 모두 24 시간 전문의 상주 규정이 적용된다고 가정하면 최소 3 인 이 상의 신생아 전문의가 근무하는 NICU의 최소 개수를 추산할 수 있 다 ${ }^{33)}$. 실제로 2015년 일본의 총합주산기센터 80개의 NICU의 대부 분은 15 병상당 상근 전문의가 5 명 이상이었고 부족하다고 답한 59 개의 센터의 상근 의사도 평균 6.9 명이었다 ${ }^{34}$. 우리나라는 3 인 이상 신생아 전문의가 근무하는 NICU는 13 개소에 불과하고 스위스 기준 으로 볼 때 level 3 의 인력 기준, 즉 최소 4 인 이상의 신생아 전문의 가 있는 NICU는 3개소에 불과하다. 이는 NICU 신생아 전문의 인력 에 대한 획기적 증원과 재배치가 선행되지 않는 이상 국내 전역에 서 신생아 전문의의 지속적 진료를 기대하기에는 시기상조인 현실
을 보여준다.

본 연구에서 주목할 것은 신생아 의사의 업무 강도에 대한 NICU 진료 등급별 분석 결과이다. 신생아 전문의당 병상 수는 진료 등급 과 무관하였으며 오히려 level $2 \mathrm{NICU}$ 에서의 담당 환자 수가 level 3 이상의 담당 환자 수에 비하여 적어 통상적 예측과 어긋났다. Level $4 \mathrm{NICU}$ 가 level 3 에 비해서 비록 병상 가동률이나 VLBWI 연간 입원 수 등 중증도 지표가 유의하게 높았음에도 불구하고 1 인당 NICU 병 상 수나간호 인력 등급 등 더 높은 중증도를 보완할 수 있는 의사 및 간호 인력 공급의 차이가 발견되지 않았다. 다만 평균 환자 위중도 점수의 차이가 두 군 간에 통계적으로 유의하지 않은 점은 본 설문 에서 level 3 와 level 4 의 구분이 정확하지 않을 가능성도 배제할 수 없다. 무엇보다 이번 결과는 신생아 전문의 이외에 전임의, 소아청 소년과 전공의, 입원 전담의(hospitalist), 전문 간호사 등 일차 진료 와 관련된 다양한 직종이 포함된 분석이 아니다. 일본은 2012년 기 준으로 NICU 전임 의사 약 1,283 명이 등록되어 있다. 이 중 신생아 전문의 385 명을 제외한 나머지 인원은 NICU 진료를 전담하는 전문 의로서 국내 입원 전담의 개념과 유사하다 ${ }^{35)}$. 미국은 간호사의 일 차 진료 참여가 공식적으로 인정되며 신생아 전문간호사(neonatal nurse practitioner, NNP)와 진료보조인력(physician assistant)이 NICU 진료의 주축을 담당한다. 2016년 기준으로 미국에는 5,433명 의 NNP가 등록되어 있고 전체 전문 간호사(nurse practitioner)의 약 $3 \%$ 를 차지한다 ${ }^{36}$. 공인된 학위와 수련 프로그램을 거쳐 자격이 주 어지며 신생아 소생술에서부터 도관 삽입 등 다양한 침습적 시술을 담당할 뿐 아니라 대부분 주-야간 또는 24시간 단위 교대 근무 형식 으로 근무하고 있어 고위험 신생아에 대한 지속적 진료 제공에 크게 기여하고 있다. 물론 국가별로 신생아 진료 담당 인력들의 역할에 대한 차이는 엄연히 존재한다. 그럼에도 불구하고 분만, 중환자실 진료, 퇴원 후 추적 관찰, 가족 지지 등 어느 의료 현장보다 많은 의 료 인력이 요구되는 신생아 진료에서 직종을 초월한 협업이 적극 권 장되고 있는 세계적 흐름은 부인할 수 없다.

우리 연구는 몇 가지 제한점이 있다. 첫째, 공식적인 확인 조사가 아닌 설문 조사 연구에서 가질 수밖에 없는 회상 기억 오류의 가능 성이다. 둘째, 각 기관별 인력과 VLBWI 사망률 등 주요 결과 변수와 의 연관성에 대한 분석이 없었다. 향후 한국 신생아 네트워크 자료 를 이용하여 사망과 연관된 여러 위험 요인을 보정한 후 인적 요인 이 이들의 사망률에 미치는 영향에 대한 연구가 필요할 것으로 생각 된다. 셋째, 병상 가동률, VLBWI 연간 입원 수 등 일부 자료들은 연 속변수가 아닌 구간변수로 제시되었다. 따라서 제시된 구간 내에서 의 분포가 실제 분석 결과에 영향을 미쳤을 가능성을 배제할 수 없 다.

우리나라 신생아 전문의 인력공급은 국제적 표준에 미치지 못하 였고 대부분 NICU는 지속적 전문 진료 공급이 불가능한 수준이었 다. 신생아 전문의의 획기적 증원을 전제로 향후 효율적인 전국 신 
생아 진료체계 구축을 위한 배치 및 활용 방안에 대한 추가적 연구 가 필요하다.

\section{ARTICLE INFORMATION}

\section{Ethical statement}

This study was approved by the Institutional Review Board of Asan Medical Center, which granted a waiver of informed consent requirement for this study (IRB No. 2020-0337).

\section{Conflicts of interest}

No potential conflict of interest relevant to this article was reported.

\section{Author contributions}

Conception or design: B.S.L., K.S.K.

Acquisition, analysis, or interpretation of data: B.S.L., J.W.L., Y.S.C.

Drafting the work or revising: B.S.L., J.W.L., K.S.K.

Final approval of the manuscript: K.S.K.

\section{ORCID}

Byong Sop Lee https://orcid.org/0000-0002-1347-4200

Jae Woo Lim https://orcid.org/0000-0003-2001-0727

Ki-Soo Kim https://orcid.org/0000-0003-1547-5220

\section{Acknowledgments}

None

\section{REFERENCES}

1. Harrison W, Goodman D. Epidemiologic trends in neonatal intensive care, 2007-2012. JAMA Pediatr 2015;169:855-62.

2. Shin SM, Namgung R, Oh YK, Yoo BH, Jun YH, Lee KH. A survey on the current status of neonatal intensive care units for the planning of regional perinatal care system in Korea. J Korean Soc Neonatol 1996;3:1-8.

3. Han YJ, Seo K, Shin SM, Lee SW, Do SR, Chang SW. Low birth weight outcomes and policy issues in Korea. Sejong: Korea Institute for Health and Social Affairs, 1999.

4. Shin SM. Current status and a prospect of neonatal intensive care units in Korea. J Korean Med Assoc 2006;49:983-9.

5. Shin SM. Current status of neonatal intensive care units in
Korea. Korean J Pediatr 2008;51:243-7.

6. Kang BH, Jung KA, Hahn WH, Shim KS, Chang JY, Bae CW. Regional analysis on the incidence of preterm and low birth weight infant and the current situation on the neonatal intensive care units in Korea, 2009. J Korean Soc Neonatol 2011;18:70-5.

7. Kim H. Evaluation of performance and efficiency in operation of neonatal intensive care unit. Sejong: Ministry of Health and Welfare, 2016.

8. Shim JW, Jin HS, Bae CW. Changes in survival rate for very-lowbirth-weight infants in Korea: comparison with other countries. J Korean Med Sci 2015;30(Suppl 1):S25-34.

9. Lee JH, Noh OK, Chang YS; Korean Neonatal Network. Neonatal outcomes of very low birth weight infants in Korean Neonatal Network from 2013 to 2016. J Korean Med Sci 2019;34:e40.

10. Korean Statistical Information Service. Birth statistics [Internet]. Daejeon: KOSIS; 2020 [cited 2020 May 11]. Available from: http://www.kosis.kr/index/index.do.

11. Song IG, Shin SH, Kim HS. Improved regional disparities in neonatal care by government-led policies in Korea. J Korean Med Sci 2018;33:e43.

12. Chang YS. Moving forward to improve safety and quality of neonatal intensive care in Korea. J Korean Med Sci 2018;33:e89.

13. Kim BI. Development of evaluation method and criteria for the appropriateness of neonatal intensive care unit. Wonju: Health Insurance Review and Assessment Service, 2017.

14. American Academy of Pediatrics Committee on Fetus and Newborn. Levels of neonatal care. Pediatrics 2012;130:587-97.

15. Rogowski JA, Staiger DO, Patrick TE, Horbar JD, Kenny MJ, Lake ET. Nurse staffing in neonatal intensive care units in the United States. Res Nurs Health 2015;38:333-41.

16. American Academy of Pediatrics. Committee on Fetus and Newborn. Manpower needs in neonatal pediatrics. Pediatrics 1985;76:132-5.

17. American Academy of Pediatrics. Committee on Fetus and Newborn. Committee of the Section on Perinatal Pediatrics. Estimates of need and recommendations for personnel in neonatal pediatrics. Pediatrics 1980;65:850-3.

18. Thompson LA, Goodman DC, Little GA. Is more neonatal in tensive care always better? Insights from a cross-national comparison of reproductive care. Pediatrics 2002;109:1036-43.

19. Goodman DC, Fisher ES, Little GA, Stukel TA, Chang CH, Scho endorf KS. The relation between the availability of neonatal intensive care and neonatal mortality. N Engl J Med 2002;346: 1538-44

20. Tucker J; UK Neonatal Staffing Study Group. Patient volume, staffing, and workload in relation to risk-adjusted outcomes in a random stratified sample of UK neonatal intensive care units: a prospective evaluation. Lancet 2002;359:99-107.

21. Han SJ. High-risk maternal and newborn integrated care centers: status and issues on aspect of pediatric surgery. Korean 
J Perinatol 2014;25:68-74.

22. Verloove-Vanhorick SP, Verwey RA, Ebeling MC, Brand R, Ruys $\mathrm{JH}$. Mortality in very preterm and very low birth weight infants according to place of birth and level of care: results of a national collaborative survey of preterm and very low birth weight infants in The Netherlands. Pediatrics 1988;81:404-11.

23. Phibbs CS, Bronstein JM, Buxton E, Phibbs RH. The effects of patient volume and level of care at the hospital of birth on neonatal mortality. JAMA 1996;276:1054-9.

24. Phibbs CS, Baker LC, Caughey AB, Danielsen B, Schmitt SK, Phibbs RH. Level and volume of neonatal intensive care and mortality in very-low-birth-weight infants. N Engl J Med 2007; 356:2165-75.

25. Jensen EA, Lorch SA. Effects of a birth hospital's neonatal intensive care unit level and annual volume of very low-birthweight infant deliveries on morbidity and mortality. JAMA Pediatr 2015;169:e151906.

26. Poets CF, Bartels DB, Wallwiener D. Patient volume and facilities measurements as quality indicators of peri- and neonatal care: a review of data from the last 4 years. Z Geburtshilfe Neonatol 2004;208:220-5.

27. Bartels DB, Wypij D, Wenzlaff P, Dammann O, Poets CF. Hospital volume and neonatal mortality among very low birth weight infants. Pediatrics 2006;117:2206-14.

28. Chung JH, Phibbs CS, Boscardin WJ, Kominski GF, Ortega AN, Needleman J. The effect of neonatal intensive care level and hospital volume on mortality of very low birth weight infants. Med Care 2010;48:635-44.

29. Lasswell SM, Barfield WD, Rochat RW, Blackmon L. Perinatal regionalization for very low-birth-weight and very preterm infants: a meta-analysis. JAMA 2010;304:992-1000.
30. Shim JW, Kim MJ, Kim EK, Park HK, Song ES, Lee SM, et al. The impact of neonatal care resources on regional variation in neonatal mortality among very low birthweight infants in Korea. Paediatr Perinat Epidemiol 2013;27:216-25.

31. British Association of Perinatal Medicine. Optimal arrange ments for neonatal intensive care units in the UK including guidance on their medical staffing: a framework for practice (2014) [Internet]. London: BAPM; 2014 [cited 2020 May 11]. Available from: https://www.bapm.org/resources/31-optimalarrangements-for-neonatal-intensive-care-units-in-theuk-2014.

32. Swiss Society of Neonatology. Standards for levels of neonatal care in Switzerland: revised version 14.3. 2019 [Internet]. Basel: Swiss Society of Neonatology; 2019 [cited 2020 May 11]. Available from: https://www.neonet.ch/application/files/ 7715/ 6880/5956/Level_Standards_2019-03-14.pdf.

33. Bae CW. Bench-marking of Japanese perinatal center system for improving maternal and neonatal outcome in Korea. Korean J Perinatol 2010;21:129-39.

34. Ministry of Health, Labour and Welfare. Report on NICU maintenance and number of doctors in NICU [Internet]. Tokyo: Ministry of Health, Labour and Welfare; 2015 [cited 2020 May 11]. Available from: https://www.mhlw.go.jp/file/05-Shingik ai-10801000.../0000096037.pdf.

35. Ministry of Health, Labour and Welfare. Data on the current status of perinatal medical system [Internet]. Tokyo: Ministry of Health, Labour and Welfare; 2015 [cited 2020 May 11]. Available from: https://www.mhlw.go.jp/file/05-Shingikai-10801000Iseikyoku-Soumuka/0000096037.pdf.

36. Staebler S, Bissinger R. 2016 Neonatal nurse practitioner work force survey: report of findings. Adv Neonatal Care 2017;17: 3316. 